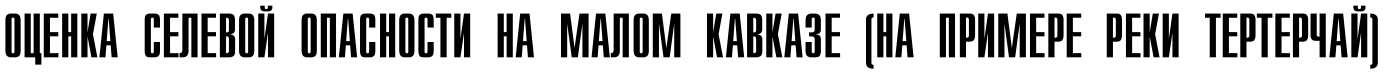

\author{
С. А. Тарихазер, Г. Л. Набиев \\ Институт географии им. ак. Г. А. Алиева НАНА, Баку, Азербайджан \\ kerimov17@gmail.com, nabiyev-qasan@rambler.ru
}

\begin{abstract}
В статье рассматриваются геолого-геоморфологические и климатические условия формирования селей на юго-восточном склоне Малого Кавказа на примере реки Тертерчай и дается оценка их активности в условиях изменения климата. По характеру выносимой массы селевые потоки относятся к водокаменным, в геолого-геоморфологическом строении их бассейнов участвуют малоустойчивые горные породы. Проведено исследование бассейна реки Тертерчай на основе материалов дешифрирования космических снимков (КС) для выявления степени селевой опасности и типа селевых потоков. Проанализированы метеорологические условия, которые вызывают сели в бассейне реки Тертерчай. Выявлены количественные показатели селеобразующих дождей. Исследовано вертикальное распределение обильных осадков с суточной суммой $\geq 20$ мм. Установлена связь селей с макроциркуляционными процессами над Европой и Западной Сибирью. С этой целью были использованы типы циркуляции по Г. Я. Вангенгейму и Б. Л. Дзердзеевскому. В исследуемом бассейне образование селей обусловлено макроциркуляционными условиями и интенсивными ливнями, экспозицией горных хребтов к ведущим воздушным потокам. Согласно анализу, в период селеобразования в Азербайджане отмечается резкое понижение температуры воздуха как на поверхности земли, так и на всех высотах тропосферы (особенно до поверхности 300-200 гПа), увеличение удельной и относительной влажности. В результате наблюдается неустойчивая стратификация атмосферы, что является причиной образования интенсивных селеобразующих ливневых осадков.
\end{abstract}

Ключевые слова: селевой поток, селеопасность, дешифрирование, космический снимок, атмосферная циркуляция, активность, антропогенное воздействие, метеорологические условия.

\section{ESTIMATION OF MUDFLOW RISK IN THE IESSER CAUCASUS (ON EXAMPLE OF THE TERTERCHAY RIVER)}

\author{
S. A. Tarikhazer 1 , G. L. Nabiyev² \\ Institute of Geography named by acad. H.A.Aliyev of ANAS, Azerbaijan, Baku
}

In the article the geological-geomorphological and climatic conditions of mudflow formation in the south-eastern slope of the Lesser Caucasus on the example of the Terterchay River are researched and their activity under climate change conditions is estimated. According to the carried mudflow mass the mud flows are subdivided into water-stone flows, low-stability rocks are involved in the geological-geomorphological structure of the basins. Investigation of the Terterchay River basin, based on the materials of interpretation of space images (SI), revealed the degree of mudflow risk and the type of mudflows. The article also analyzed meteorological conditions that caused mudflows in the basin of the Terterchay River. Quantitative indicators of mudflow-forming rain were revealed. The vertical distribution of abundant precipitation with a daily sum of $\geq 20 \mathrm{~mm}$ was investigated. The connection of the mudflows with macrocirculation processes over Europe and Western Siberia was established. To do that types of circulation according to G.Ya. Wangengheim and B. L. Dzerdzeevsky were used.

Keywords: mudflow, mudflow hazard, interpretation, space image, atmospheric circulation, activity, anthropogenic impact, meteorological conditions.

\section{Введение}

Изучение селевых процессов важно для Азербайджана. По официальным данным, $13 \%$ территории страны (более 10 тыс. км²) подвержено воздействию опасных геодинамических процессов, в том числе в зоне действия селевых процессов находится 1.2 млн га территории. В настоящее время в Азербайджане происходит процесс интенсивного освоения горных территорий, что вызывает увеличение природных стихийно-разрушительных процессов, к которым относятся и селевые потоки, наносящие огромный ущерб населению и хозяйству республики. Селевые явления распространены почти во всех горных и предгорных районах страны. Нередко сели имеют катастрофический характер, вызывая разрушения населенных пунктов и инженерных сооружений в долинах и в местах выхода на предгорные равнины.

7 мая 2015 г. в Азербайджане в результате выпадения ливневых дождей в горных районах юго-восточного склона Малого Кавказа прошел сель, который создал серьезные проблемы населенным пунктам Тертерского и Бардинского районов. Селевые потоки разрушили несколько домов вынужденных переселенцев. Нанесен серьезный ущерб около 20 домам, разрушены приусадебные участки, автомобильный и железнодорожный мосты, дороги, затоплены подвалы домов, погиб домашний скот. Часть Бардинского района осталась без электроэнергии. Сель смывал оказавшиеся на его пути автомобили. Кроме того, селевые потоки принесли с собой с оккупированных земель Азербайджана и нейтральных территорий линии соприкосновения множество неразорвавшихся противотанковых мин ПМН-72. Такая крупномасштабная ситуация сложилась здесь впервые за последние 30 лет. Для устранения последствий природного бедствия было привлечено большое количество техники, однако не сразу удалось осуществить необходимые мероприятия. Подобные явления в несколько меньшем мас- 
штабе были зафиксированы и на прилегающих территориях.

Для поддержания безопасного функционирования любой системы, включающей природные ландшафты и антропогенные объекты, в первую очередь должны определяться вероятность риска и ее нарушения. Риски требуется выявить и оценить, не дожидаясь последствий - влияния реализованного риска на экосистему [4].

\section{Объекты и методы исследования}

Задачей исследования является изучение основных причин формирования селей на р. Тертерчай на основе материалов дешифрирования космических снимков (KC) и выявление степени селевой опасности и типа селевых потоков.

На территории Азербайджана селевые процессы развиваются в сложной природно-ландшафтной обстановке, где решающее значение имеют геолого-геоморфологические и гидрометеорологические факторы, а также антропогенная деятельность (перевыпас скота, вырубка лесов, добыча полезных ископаемых, сельскохозяйственная деятельность и др.). Кроме того, в последние десятилетия в горных районах активно развивается рекреационно-туристическая индустрия, в связи с чем все больше объектов инфраструктуры, а именно здания, автодороги и др. строятся без надлежащего учета опасных экзогеоморфологических процессов, в том числе и на селеопасных участках. В результате геолого-геоморфологические системы в процессе природопользования могут частично или полностью трансформироваться, что в конечном счете может привести к обострению взаимодействий человека с окружающей средой. Могут возникнуть районы экологического бедствия, способные привести к серьезным экологическим и социально-экономическим последствиям. В связи с этим проблемы изучения опасных природных и природно-антропогенных процессов, а также их картографирование становятся актуальными. Одним из эффективных методов для этих исследований является экологогеоморфологическое картографирование на основе интерпретации материалов дешифрирования космических снимков (КС) и аэрофотоснимков (АС) с использованием ландшафтно-индикационных признаков. С помощью данного метода можно точно установить положение районов развития комплекса экзогеоморфологических процессов, их границы и дать оценку степени их опасности [2]. Следовательно, все большее значение имеет повышение точности прогноза развития и учета селеопасных процессов. В ходе исследования нами был применен одновременный метод дешифрирования. КС были взяты со спутника Landsat-8. Разрешение сцен - 30 м (панхроматический -15 м). Снимки были сделаны в ближней инфракрасной зоне (OLI и TIRS).

\section{Результаты исследований}

Одним из наиболее репрезентативных для изучения селевых процессов и комплексов районов Малого Кавказа является юго-восточный склон, а именно бассейн p. Тертерчай. Здесь по характеру выносимой массы сели являются водокаменными. В геологическом строении территории принимают участие инженерно-геологические формации магматических (интрузивная и эффузивная), метаморфических (гранулитовая) и осадочных (терригенно-карбонатная и вулканогенно-конгломератовая) пород. Интрузивные породы представлены в основном дунита- ми, перидотитами, пироксенитами и серпентинами. Породы часто разбиты многочисленными разнонаправленными трещинами. Магматические эффузивные породы представлены базальтами, туфами, залегающими на грубообломочном элювии подстилающих пород. Все эти комплексы сверху перекрыты рыхлыми четвертичными отложениями различного генезиса, среди которых выделяются аллювиально-пролювиальные, пролювиально-делювиальные, коллювиально-делювиальные отложения -- пески, галечники, супеси, суглинки. Мощность отложений достигает 6-8 м. В зависимости от состава пород коренной основы литологический состав их изменяется от обломочных до песков и супесей на юрских и меловых осадочных породах. Перечисленные условия являются благоприятными факторами для развития выветривания, гравитационных процессов (обвалы, осыпи, оползни и др.), которые могут и воздействовать на инженерно-технические сооружения, осложняя их эксплуатацию, и участвовать в селеформировании.

Современный рельеф юго- восточного склона Малого Кавказа характеризуется зоной высоких горных хребтов общекавказского простирания (Гарабагское вулканическое нагорье) и зоной относительно пониженного рельефа (Гейча-Акеринская и др.). Наличие высоких горных хребтов, вулканических нагорий, глубоких межгорных долин и котловин обусловливают резкую расчлененность рельефа. К югу от Шахдагского и Муровдагского хребтов в субмеридиональном направлении простирается Восточно-Гейчинский хребет, характеризующийся интенсивным эрозионным расчленением. Основными формами Гарабагского вулканического нагорья являются вулканические массивы и щиты (Беюк Ишыглы, Гызылбогаз), лавовые потоки и плато, шлаковые конусы. В центральной части исследуемой территории простирается Гарабагский хребет, для водораздельной части которого характерно наличие ряда кулисообразно расположенных горных вершин - Гырхгыз, Беюк Гирс (2725 м) и др. В формировании современной геоморфологической обстановки юговосточного склона Малого Кавказа большую роль сыграли глубинные разломы - Гейча-Гарабагский, Гарабагский, Лачин-Башлыбельский и др. Однако в современном рельефе немалую роль играют и более мелкие разрывные нарушения - сбросы, надвиги и др. Кроме того, в проявлении экзодинамических рельефообразующих процессов огромное значение имеют знак и амплитуда тектонических движений и разрывные нарушения. Тектонические разрывы и разломы, соответствуя границам отдельных блоков, подвержены неравномерным движениям. Вместе с тем тектоническая трещиноватость играет значительную роль в развитии процессов выветривания, создавая зону дробления и способствуя тем самым накоплению рыхлообломочного материала в селевых очагах $[1,5]$. К периодам усиления поднятий (до $+9 \ldots+12$ мм/год на Малом Кавказе) и активизации сейсмичности (до $7-8$ баллов) часто приурочена и активизация таких опасных экзодинамических процессов, как оползни, обвалы, осыпи и др., которые, в свою очередь, подпитывают рыхлообломочным материалом сели, угрожающие населенным пунктам Тертерского и Бардинского районов. Высокая селеопасность здесь также вызвана раздроблением крупных продольных ступеней-блоков поперечными разрывными нарушениями. Разрывы, прерывая линейность продольных блоков, определяют морфологическое расчленение юго-восточного склона Малого Кавказа и создают благоприятные ус- 
ловия для интенсивного развития экзодинамических процессов в пределах отдельных поперечных блоков.

В юго-восточной части Малого Кавказа речная сеть имеет сложный рисунок, характеризуется рядом особенностей, обусловленных орографией, климатом, почвенно-растительным покровом и др. условиями. Наибольшая густота речной сети встречается в среднегорном поясе $1000-2500$ м $-1-2 \mathrm{kм} / \mathrm{Kм}^{2}$ [8]. Наименее развита речная сеть на Гарабагском вулканическом нагорье. Реки имеют восточное и юго-восточное направления, характеризуются сложным строением и по соотношению со структурами расчленены на продольные и поперечные участки, т. е. древние и молодые.

Морфология речных долин юго-восточного склона Малого Кавказа определяется рядом факторов: структурными, литолого-петрографическими особенностями речных бассейнов, водностью рек и др. В верхнем течении долины рек имеют глубокую ущелеобразную форму, ступенчатое строение русел, загроможденных глыбами коренных пород, обрушившихся с прилегающих склонов. В высокогорной зоне речные долины имеют форму трогов, а реки со склонов массива Далидаг (3616 м) начинаются из небольших каровых озер. В пределах легкоразрушаемых горных пород в истоках рек развиты эрозионные воронкообразные долины с относительно пологими склонами, расчлененными многочисленными притоками. В среднегорном поясе долины рек глубокие, с выпуклыми склонами, крутизна которых увеличивается в их нижней части [3]. На всех участках долин рек юго-восточного склона Малого Кавказа развиты надпойменные террасы различного генезиса - аккумулятивные, эрозионные, структурные и др., различной сохранности и литологического строения. Террасы характеризуются прерывистым простиранием и лучше всего выражены в котловинах расширенных долин рек. На юго-восточном склоне Малого Кавказа мощные конусы выноса pp. Тертерчай, Хачынчай, Гаргарчай, Акери и др. свидетельствуют о том, что здесь в прошлом также проходили структурные сели. Селеносные потоки наблюдаются на pp. Тертерчай, Гаргарчай, Акери и др.

Как видно из вышеизложенного материала, в исследуемом селеопасном районе существуют благоприятные геоморфологические, почвенно-растительные и другие условия. Однако и здесь главная роль в селеобразовании принадлежит синоптико-климатическим факторам, которые приводят к выпадению интенсивных ливневых осадков. Следует отметить, что исследователи подходили к решению этого вопроса разными путями. Одни авторы пытались выявить условия образования селей методом Г. Я. Вангенгейма [6], Б. Л. Дзердзеевского [7], другие учитывали направления вторжения воздушных масс с северных районов, воздействия приземных антициклонов, с выходами южных циклонов и местной циркуляцией, с различными высотными полями и др. Большинство связывало образование ливней и селей с перемещением с севера антициклонов и холодных фронтов. Некоторые учитывали влажность и упорядоченные вертикальные движения воздуха в образовании ливней.

Мы не согласны с мнением А. Д. Эйюбова [8] и А. А. Мадатзаде [9], принимающих обильные ливни за конвективные осадки местного происхождения. Судя по современной теории влагооборота, местная циркуляция не может дать такие ливневые осадки, которыми вызывалось селеобразование. Сущность местной циркуляции заключается в том, что быстрое нагревание воздуха в призем- ном слое приводит к сильному испарению и образованию кучево-дождевых облаков, дающих ливни. Следует отметить, что в таких процессах в осадкообразовании присутствует незначительная часть местной влаги, а основная часть влаги приносится воздушными массами, вторгающимися извне. Экстремальные значения селеобразующих дождей над исследуемой территорией колеблются в пределах 22-60 мм/сутки с ливневой частью.

На Малом Кавказе, в том числе и в бассейне р. Тертерчай, сели бывают кратковременными. Почти $91 \%$ селей имеют продолжительность от 1 до 4 часов, а остальные 4-6 часов. Максимум селей приходится на вечерние часы (18.00-22.00). Образования селей в вечерние часы, а также их внезапность увеличивают последствия их прохождения и чрезвычайно усложняют наблюдения за ними. Если можно говорить о соответствии хода селевых явлений ходу ливней, то в отношении повторяемости селей проводить подобные аналогии с ливнями нельзя, т. к. для образования селя помимо выпадения атмосферных осадков необходимо также скопление достаточного количества рыхлообломочного материала.

Исследуемой район по повторяемости обильных осадков превышает другие селеопасные районы Малого Кавказа. Здесь особенно отличается территория Верхнего Гарабага. Основной максимум осадков наблюдается в маеиюне, а минимум - в августе. В бассейне р. Тертерчай ход обильных осадков почти совпадает с ходом прохождения селевых потоков, т. е. максимум селей наблюдается именно в период максимальной повторяемости обильных осадков с суточной суммой более 20 мм. С увеличением высоты над поверхностью число дней с такими осадками увеличивается. На высоте 1500-1600 м число таких дней составляет 5-10, а выше количество дней уменьшается (до 5 дней) (рис. 1).

Причиной увеличения повторяемости обильных осадков в бассейне р. Тертерчай помимо других факторов является форма рельефа, которая способствует накоплению холодных и влажных масс воздуха, вторгающихся с запада и отчасти с востока. В теплом полугодии здесь обильные осадки являются ливневыми. Несмотря на то, что в исследуемом районе наблюдается большая повторяемость ливневых осадков, сели образуются редко. Это объясняется тем, что здесь склоны гор покрыты в большинстве случаев лесами и другими видами растительности, а также относительно малой крутостью склонов, которая уступает крутости склонов в других селеопасных районах Малого Кавказа. В исследуемом бассейне образование селей обусловлено макроциркуляционными условиями и интенсивными ливнями, экспозицией горных хребтов к ведушим воздушным потокам.

В большинстве случаев в дни выпадения селеобразующих ливневых осадков в средней тропосфере над территорией Южного Кавказа господствовали юго-западные и западно-юго-западные воздушные течения. В дни селеобразования высотная фронтальная зона проходит через территории Южного Кавказа, при развитии атмосферных процессов она усиливается и горизонтальная разность температур в ней превышает нередко 8-10\%1000 км. Согласно анализу, при всех процессах, приводящих к вторжению холодных и влажных масс воздуха, на территории Южного Кавказа, в частности Азербайджана, в период селеобразования отмечается резкое понижение температуры воздуха как на поверхности земли, так и на всех высотах тропосферы (особенно до поверхности 300-200 гПа), увели- 


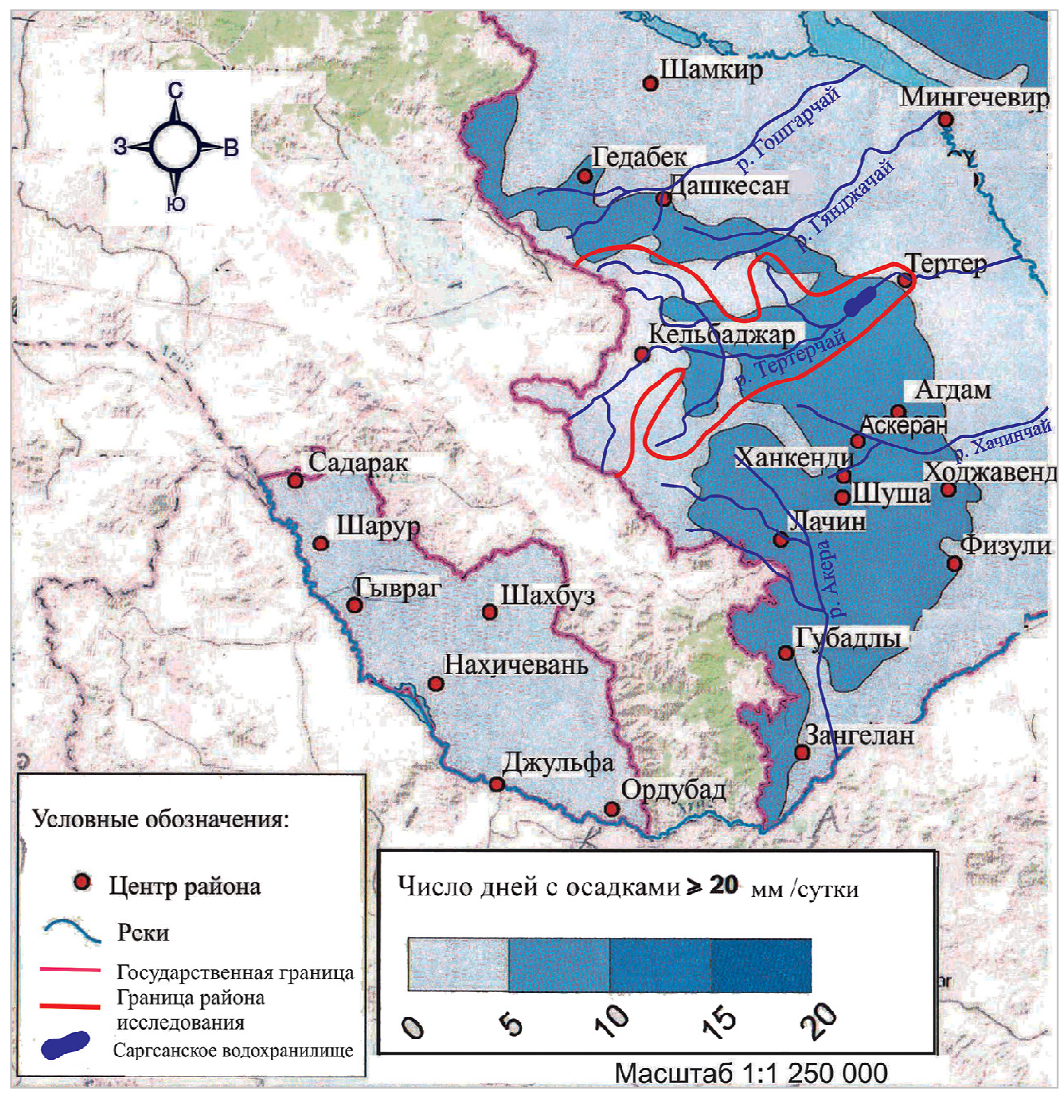

Рис. 1. Распределение числа дней с осадками $\geq 20$ мм/сутки в селеопасные периоды в районе Малого Кавказа

Fig.1. The distribution of the number of days with precipitation $\geq 20 \mathrm{~mm} /$ day in the mudflow periods in the region of the Lesser Caucasus

чение удельной и относительной влажности. В результате наблюдается неустойчивая стратификация атмосферы, что важно для образования интенсивных селеобразующих ливневых осадков.

Охарактеризуем наиболее селеносную реку исследуемой территории - p. Тертерчай, которая от других рек юго- восточного склона Малого Кавказа отличается по частоте и масштабности проявления (рис. 2, табл.). Последние исследования здесь проводились в 70-80-е годы прошлого столетия. На КС нами выявлено резкое расширение площадей селевых очагов в среднегорной и высокогорной зонах, что связано с вырубкой лесов, добычей золотоносных и медных руд, а также сожжением пастбищ на площади около 18 тыс. га.

Бассейн р. Тертерчай охватывает площадь в 2650 км², пересекая ряд различных тектонических структур. По продольному профилю р. Тертерчай делится на несколько участков. Ее истоки расположены в высокогорной зоне интенсивно расчлененного и крутосклонного рельефа, составляющего часть области центрального сводового поднятия Малого Кавказа. Значительная площадь верховьев р. Тертерчай покрыта вулканическими лавами. Характером обнажений лавовых потоков, образующих отвесные склоны, обусловливается морфология левого берега долины р. Тертерчай на всем ее протяжении к северу от источника Истису. Здесь, на левом берегу реки, располагается 45-метровая цокольная терраса, сложенная крупными валунно-галечными отложениями. По правому берегу реки на той же высоте расположена терраса, которая сложена травертинами. Ниже по течению распространены многочисленные лавовые осыпи и конусы выносов пра- вых притоков р. Тертерчай. Вся долина реки имеет форму глубокого V-образного вреза.

В районе города Кельбаджар располагается терраса, погребенная потоками лав, которая сложена слабо отсортированными валунно-галечными отложениями мощностью 30-35 м. Общая глубина эрозионного вреза долины p. Тертерчай от бровки лавового потока равна 125 м [3]. Ниже города Кельбаджар р. Тертерчай протекает в узком $\mathrm{V}$-образном ущелье, местами переходящем в типичный каньон. К каньонообразному участку относится часть долины реки, пересекающей северо-западную часть Гарабагского хребта, выполненная известняками, образующими отвесные и высокие скалистые склоны долины. Здесь широко распространены осыпные, россыпные и обвальные процессы. В пределах Атеркского участка р. Тертерчай протекает в широкой террасированной долине. Данный участок в структурном отношении отвечает юго-восточной части Тоурагачайского синклинория и Тертерскому поперечному разлому. Здесь развиты аккумулятивные и эрозионно-аккумулятивные террасы высотой 1.5-2, 1012, 30, 50, 75-80, 100, 150 м. При выходе из гор в пределы Гарабагской степи р. Тертерчай образует мощный конус выноса, сложенный галечными отложениями. Обычно галька полуокатанная, округлая, но встречается и плоскоокатанная галька.

\section{Выводы}

На юго-восточном склоне Малого Кавказа водокаменные сели практически имеют повсеместное распространение. Существенная роль в образовании селевых явлений на исследуемой территории наряду с геолого-гео- 

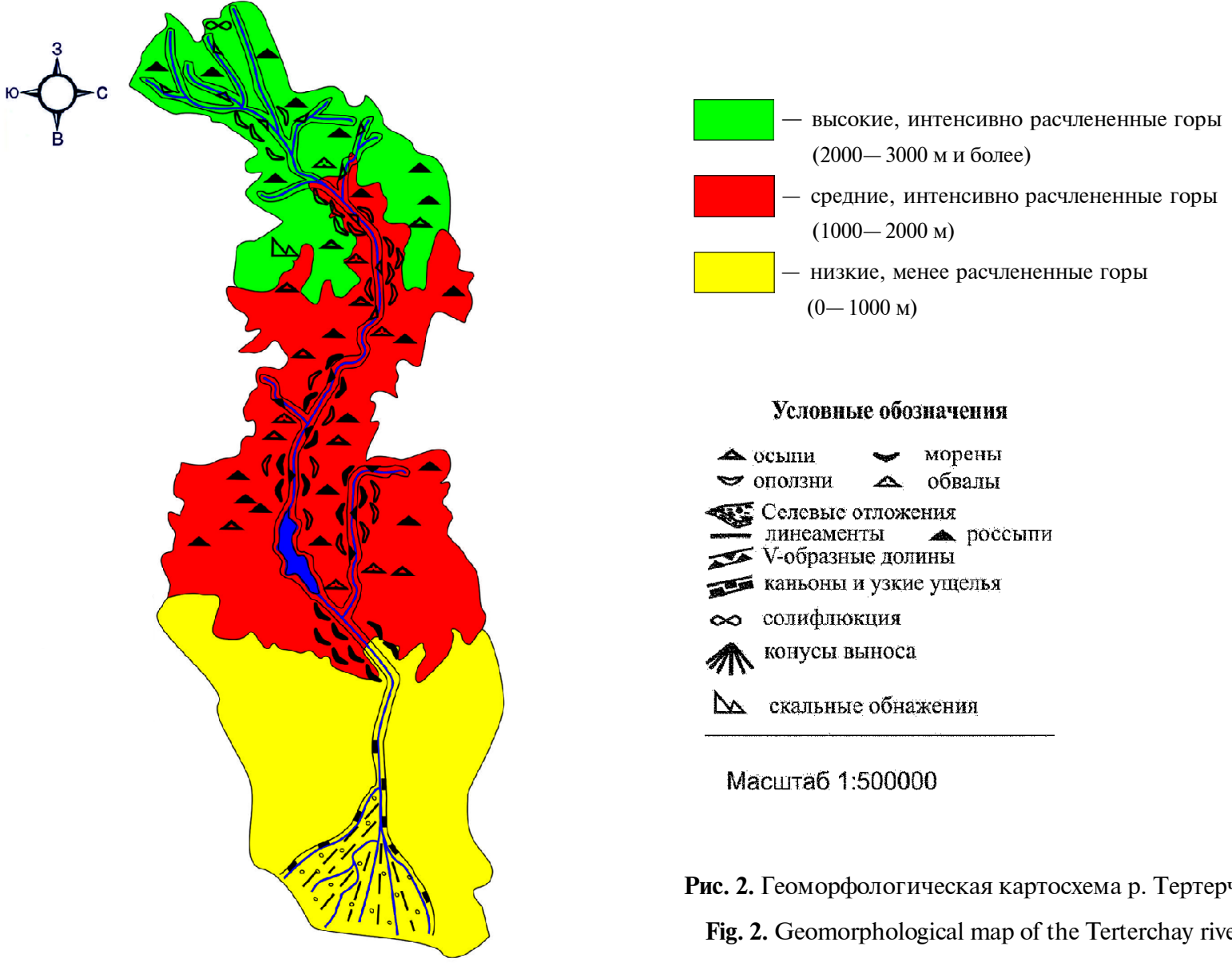

Условные обозначения

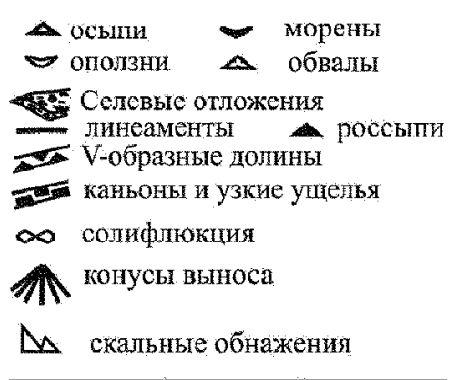

Масштаб 1:500000

Рис. 2. Геоморфологическая картосхема р. Тертерчай

Fig. 2. Geomorphological map of the Terterchay river

Даты прохождения наиболее опасных селевых потоков на р. Тертерчай

Date of occurrence of the most dangerous mudflows at the Tertechay River

\begin{tabular}{|c|c|c|c|c|c|}
\hline № & $\begin{array}{l}\text { Даты прохож- } \\
\text { дения селя } \\
\text { Dates of mudflow } \\
\text { occurrence }\end{array}$ & $\begin{array}{l}\text { Время прохож- } \\
\text { дения селя (часы) } \\
\text { Time of mudflow } \\
\text { occurrence (hours) }\end{array}$ & $\begin{array}{c}\text { Продолжитель- } \\
\text { ность селя (часы) } \\
\text { Duration } \\
\text { of mudflow (hours) }\end{array}$ & $\begin{array}{c}\text { Причины } \\
\text { селя } \\
\text { Reasons }\end{array}$ & $\begin{array}{l}\text { Последствия селя } \\
\text { Consequencies }\end{array}$ \\
\hline 1 & $10.05 .1963 г$ & $14^{00}$ & 2 & $\begin{array}{l}\text { Ливень } \\
\text { Ileavy rain }\end{array}$ & $\begin{array}{l}\text { Материальный ущерб составил } 11 \text { млн руб. } \\
\text { Material damage amounted to } 11 \text { million rubles }\end{array}$ \\
\hline 2 & 07.07 .1974 г. & $20^{00}$ & $2-3$ & $-1 /-$ & \begin{tabular}{|l|} 
Pазрушено несколько домов близ р. Тертерчай \\
Several houses were destroyed near the Terterchay river
\end{tabular} \\
\hline 3 & 28.09 .2009 г. & ночь / at night & $4-5$ & $-/ /-$ & $\begin{array}{l}\text { Затоплены и повреждены жилые дома села Гасымбейли } \\
\text { Residential houses of Gasimbeyli village were flooded and } \\
\text { damaged }\end{array}$ \\
\hline 4 & 01.10 .2009 г. & $23^{\frac{00}{0}}$ & $3-4$ & $-/ /-$ & $\begin{array}{l}\text { Затоплены жилые дома села Бурудж. Разрушены } \\
\text { несколько домов, автомобильная и железная дороги } \\
\text { Houses were flooded of the village of Buruj. Several houses } \\
\text { were destroyed, roads and railways }\end{array}$ \\
\hline 5 & $26.05 .2010 \mathrm{r}$ & ночь / at night & 5 & $-1 /-$ & $\begin{array}{l}\text { Повреждено несколько жильх домов села Хусенли } \\
\text { Several houses were damaged in the village of Husenil }\end{array}$ \\
\hline 6 & 31.10 .2014 г. & $22^{00}$ & $2-3$ & $-/ /-$ & $\begin{array}{l}\text { Ущерб примерно } 100 \text { домам, затоплены приусадебные } \\
\text { угастки, подвалы домов } \\
\text { The mudflow caused damage to ahout } 100 \text { houses, flooded } \\
\text { household plots, basements of houses }\end{array}$ \\
\hline 7 & $07.05 .2015 \pi$ & $20^{000}$ & 3 & -11 & $\begin{array}{l}\text { Разрушены приусадебные участки, автомобильный и } \\
\text { железнодорожный мосты, дороги, затоплены подвалы } \\
\text { домов, погиб домашний скот. Селевье потоки принесли } \\
\text { с собой с оккупированных земель Азербайджана } \\
\text { множество неразорвавшихся противотанковых мин } \\
\text { ПMН-72 } \\
\text { Household plots, automobile and railway bridges, roads, } \\
\text { basements or houses were flooded, livestock were destroyed. } \\
\text { Mudflows brought with them many unexploded anti-tank } \\
\text { mines PMN-72 from the occupied lands of Azerbaijan }\end{array}$ \\
\hline
\end{tabular}


морфологическими и климатическими факторами принадлежит антропогенному воздействию. Происшедшее 7 мая 2015 г. селевое событие в очередной раз подтверждает точку зрения о необходимости постоянного мониторинга стихийно-разрушительных событий на горных территориях Азербайджана. Однако эта задача не решается в силу объективных причин.

На территории Южного Кавказа, в частности Азербайджана, без вторжения холодных и влажных воздушных масс из северных и северо-западных районов Европы обильные осадки не выпадают и сели не образуются. При всех процессах холодные и влажные массы воздуха проникают на территорию республики за холодными фронтами, при меридиональных преобразованиях высотного деформационного поля тропосферы, в результате которого увеличивается значение удельной и относительной влажности, а также неустойчивость стратификации. Все эти перечисленные условия приводят к выпадению интенсивных обильных ливней и формированию селей.

\section{Литература}

1. Ализаде Э. К. Закономерности морфоструктурной дифференциации горных сооружений восточного сегмента центральной части Альпийско-Гималайской шовной зоны (на основе материалов дешифрирования КС): Автореф. док. дис. Баку, 2004, 53 с.

2. Ализаде Э. К., Тарихазер С. А. Высотно-ландшафтная обусловленность развития селевых процессов в горных геосистемах южного склона Большого Кавказа // Наука, образование, культура и информационно-просветительская деятельность - основы устойчивого развития горных территорий: Избранные материалы VIII Международ. науч.-практ. конф., 2015. № 4(26). С. 33-41.

3. Ализаде Э. К., Тарихазер С. А. Экогеоморфологическая опасность и риск на Большом Кавказе (в пределах Азербайджана). М.: МАКС Пресс, 2015. 207 с.

4. Баринов А. Ю. Геоморфологический анализ ливневой селеопасности щели Широкая Балка (Черноморское побережье Кавказа) // Геоморфология. 2010. № 2. С. 19-25.

5. Будагов Б. А. Новейшая тектоника Большого Кавказа // Рельеф Азербайджана. Баку: Элм, 1993. С. 75-78.

6. Вангенгейм Г. Я. Опыт применения синоптических методов к изучению и характеристике климата. М.: Гидрометеоиздат, 1935. 109 с.

7. Дзердзеевский Б. Л. Общая циркуляция и климат // Избранные труды. М., 1975. 288 с.

8. Эйюбов А. Д. Климатические факторы формирования селей в горах Азербайджана. Баку, 1962. С. 49-55.

9. Мадатзаде A. А. Синоптические условия выпадения обильных осадков, обусловливающих паводки в Азербайджане // Материалы V Всесоюзного совещания по изу- чению селевых потоков и мер борьбы с ними. Баку, 1962. С. $153-156$.

\section{References}

1. Alizade E. K. Zakonomernosti morfostrukturnoy differentsiatsii gornykh sooruzheniy vostochnogo segmenta tsentral'noy chasti Al'piysko-Gimalayskoy shovnoy zony (na osnove materialov deshifrirovaniya KS): avtoref. dis. ... dok. geogr. nauk (Regularities of The Morphostructural Differentiation of Mountain Structures in The Eastern Segment of The Central Part of The Alpine-Himalayan Suture Zone (Based On The Materials For Deciphering The Cs)). Synopsis of Dr. geogr. sci. diss. Baku, 2004, 53 p.

2. Alizade E. K., Tarikhazer S. A. Vysotno-landshaftnaya obuslovlennost' razvitiya selevykh protsessov $v$ gornykh geosistemakh yuzhnogo sklona Bol'shogo Kavkaza. (High-Landscape Conditionality of Development of Mudflow Processes in Mountain Geosystems of The Southern Slope of The Greater Caucasus). Proceedings of conference «Nauka, obrazovanie, kul'tura $i$ informatsionno-prosvetitel'skaya deyatel'nost'-osnovy ustoychivogo razvitiya gornykh territoriy». Vladikavkaz, 2015, V. 4 (26), pp. 33-41.

3. Alizade E. K., Tarikhazer S. A. Ekogeomorfologicheskaya opasnost' i risk na Bol'shom Kavkaze (v predelakh Azerbaydzhana) (Ecogeomorphological Danger and Risk in The Greater Caucasus (Within Azerbaijan)). Moscow, 2015, pp. 207.

4. Barinov A. Yu. Geomorfologicheskiy analiz livnevoy seleopasnosti shcheli Shirokaya Balka (Chernomorskoe poberezh'ye Kavkaza) (Geomorphological Analysis of The Mudflow Hazard of The Shirokaya Balka Gap (The Black Sea Coast of The Caucasus)). Geomorfologiya-Geomorphology, Moscow, 2010, V. 2, pp. $19-25$.

5. Budagov B. A. Noveyshaya tektonika Bol'shogo Kavkaza (The Newest Tectonics of The Greater Caucasus. in the collection «The relief of Azerbaijan»). Rel'yef Azerbaydzhana. Baku, 1993, pp. 75-78.

6. Vangengeym G.Ya. Opyt primeneniya sinopticheskikh metodov $k$ izucheniyu i kharakteristiki klimata (Experience in Applying Synoptic Methods to The Study and Characteristics of The Climate). Moscow, 1935, pp. 109.

7. Dzerdzeevskiy B. L. Obshchaya tsirkulyatsiya i klimat (General Circulation and Climate). Moscow, 1975, pp. 288.

8. Eyyubov A. D. Klimaticheskie faktory formirovaniya seley $v$ gorakh Azerbaydzhana (Climatic Factors of Mudflow Formation in The Mountains of Azerbaijan). Baku, 1962, pp. 49-55.

9. Madatzade A. A. Synoptic conditions for heavy precipitation, causing floods in Azerbaijan. In: Proceedings of $5^{\text {th }}$ All-Union Conference on the Study of Mudflows and Control Measures against them. Baku, 1962, pp. 153-156. 